\title{
Blood pressure control among hypertensive patients with and without diabetes mellitus in six public primary health care clinics in Malaysia
}

\begin{abstract}
Hypertension is a common comorbidity among diabetic patients. This study aimed to determine blood pressure (BP) control among hypertensive patients with and without diabetes. This was a cross-sectional study in 6 public primary care clinics in Wilayah Persekutuan, Malaysia. Hypertensive patients aged $\geq 18$ years and attending the clinics were selected via systematic random sampling. The BP control target was defined as $<130 / 80 \mathrm{~mm}$ $\mathrm{Hg}$ for diabetic patients and $<140 / 90 \mathrm{~mm} \mathrm{Hg}$ for nondiabetic patients. A total of 1107 hypertensive patients participated in this study and $540(48.7 \%)$ had diabetes. About one fourth $(24.3 \%)$ of the hypertensive patients with diabetes achieved BP control target, compared with $60.1 \%$ patients without diabetes $(\mathrm{P}<.001)$. Being diabetic and on $\geq 2$ antihypertensive treatments were associated with poor BP control. Attention needs to be given to these groups of patients when managing patients with hypertension.
\end{abstract}

Keyword: Antihypertensive treatment; Blood pressure control; Diabetes; hypertension; Primary care 